\title{
A supply chain resilience model for business continuity: The way forward for highly regulated industries
}

\author{
Osaro Aigbogun ${ }^{a^{*}}$, Meng Xing ${ }^{\mathrm{a}}$, Olawole Fawehinmi ${ }^{\mathrm{b}}$, Chukwuebuka Ibeabuchic, Amauche Ehido ${ }^{\mathrm{c}}$, \\ Rohana Binti Ahmad ${ }^{b}$ and Mohammed Sani Abdullahi ${ }^{\text {d }}$
}

${ }^{a}$ School of Business, Binary University of Management and Entrepreneurship, Malaysia

${ }^{b}$ Faculty of Business, Economics and Social Development, Universiti Malaysia Terengganu, Malaysia

${ }^{c}$ Faculty of Business and Management, Universiti Sultan Zainal Abidin, Malaysia

dDepartment of Business Administration, Yusuf Maitama Sule University Kano, Nigeria

A B S T R A C T

\begin{tabular}{l} 
Article history: \\
Received July 20, 2021 \\
Received in revised format \\
September 24, 2021 \\
Accepted October 292021 \\
Available online \\
November 72021 \\
\hline Keywords: \\
Business Continuity \\
Supply Chain Resilience \\
COVID-19 \\
Collaboration \\
Regulation \\
Smart-PLS
\end{tabular}

\begin{abstract}
The COVID-19 outbreak is a black swan event that has uncovered the delicateness of global supply chains and business architecture. Underpinned by the agency theory and institutional theory, a proposition for business continuity in the highly regulated pharma industry is presented in this paper. A cross-sectional quantitative study was carried out on a sample of 102 pharma supply chain executives in Malaysia. The primary data were gathered by administering a self-administered questionnaire and analyzed using the partial least squares structural equation modelling (PLSSEM). The result reveals that supply chain orientation directly influences supply chain resilience. Also, introducing collaborative regulation as a mediator in this relationship shows partial mediation. The notion of collaborative regulation as a behavioral governance mechanism is relatively new, thus, presenting interesting opportunities for further exploration of the subject matter.
\end{abstract}

\section{Introduction}

Years ago, business organizations were integrated vertically; hence, the supply chain was shorter, less complex, very predictable, and viewed as a less significant value contributor. However, supply chains are more complicated nowadays, consolidating vertical and horizontal relationships in real-time, compromising business continuity during disruptions. Supply chain disruptions are associated with supply market failures or individual supplier failures to fulfil customer demand. This is attributable to a breakdown in material supplies, information and monetary flows between an enterprise and its suppliers, thereby causing a threat to business continuity (Zsidisin, 2005). An ongoing example is disruptions in supply chains resulting from the confinement and restriction measures during the COVID-19 pandemic, an uncertainty generally viewed as a HighImpact-Low-Probability (HILP) crisis. The threat arising from this crisis and future related occurrence has forced businesses to devise risk mitigating strategies to sustain business continuity. For this reason, competition is currently not merely between supply chains but centered on the resilience of those supply chains. Business organizations today require, more than ever before, a resilient supply chain to assure business continuity.

Business continuity is an organization's capacity to guarantee its operations and core business functions are not severely disrupted by a disaster or unplanned/unwanted occurrence that compromises its critical systems (Burtles, 2016). It is key to business survival; thus, for business continuity to be assured, a significant level of resilience is required to react and adapt to whatever disruptions are encountered. Resilience is a holistic approach that combines strategic and operational factors to deliver business continuity (Blos, Wee, \& Yang, 2012). Thus, the propensity for business continuity is interconnected to the

* Corresponding author

E-mail address: osaro.aigbogun@gmail.com (O. Aigbogun)

(C) 2022 Growing Science Ltd. All rights reserved.

doi: $10.5267 /$ j.uscm.2021.11.001 
resilience of a business organization. For businesses to succeed, they need to build resilience by strengthening their supply chain orientation (Chowdry \& Quaddhus, 2016). Supply chain orientation is at the heart of business survival. It entails implementing systemic and strategic consequences of the tactical activities involved in managing product and information flow in a supply chain (Min \& Mentzer, 2004; Zailani, Premkumar, \& Fernando, 2008). It is even more significant in highly regulated industries where supply disruptions are very important to the national economy and wellbeing of the population, thus requiring broader solutions (Burger \& Warner, 2012).

The conventional propositions for achieving resilient supply chains might not be entirely sufficient in highly-regulated contexts, such as the pharma industry, where the bureaucracy of regulatory oversight complicates the challenge of disruptions in supply chains (Chatterjee \& Chaudhuri, 2021). One of such highly regulated businesses is pharmaceutical manufacturing, which has become most vulnerable to supply disruptions of starting raw materials, thus threatening its survival. More resources will be needed to manage the cascading problems from the high cost of error if this problem is ignored. For this reason, collaborative regulation has been proposed (Aigbogun, Ghazali, \& Razali, 2018; Chatterjee \& Chaudhuri, 2021). Collaborative regulation brings public and private parties on the same platform for decision making. While performing its principal role of enforcing measures, rules and conformance with standards, regulatory authorities in contemporary supply chains need to forge collaborative affiliations with the companies they regulate. The challenge here is to design resilient supply chains with collaborative relationships that sustain continuous supply and respond proactively and quickly to unavoidable disruptions.

This paper examines the mediating effect of collaborative regulation on supply chain orientation and resilience in the pharmaceutical manufacturing context. This investigation was carried out in Malaysia, an emerging economy and a key player in the Association of Southeast Asian Nations (ASEAN).

\section{Literature Review}

\subsection{Conceptualizing Supply Chain Resilience}

Research scholars have advanced trenchant arguments that support the idea that resilience confers on a system the ability/capacity to return to its initial or perhaps better performance under emergency. As such, one can infer an association between resilience and enhanced supply chain risk management/supply chain performance. Li et al. (2015) opine that resilient supply chains outdo their competitors when dealing with HILP crisis.

Per the assertion that resilient supply chains function better during HILP crisis, Scholten et al. (2014); Gölgeci \& Ponomarov (2015), and Tukamuhabwa et al. (2015) put forward the following definitions of resilience: Scholten et al. (2014, p. 212) defined resilience as the capacity of supply chains to be ready for unexpected occurrences, react to disruptions and pull through by sustaining operations and control over structures and function at an optimal level. Gölgeci and Ponomarov (2015, p. 269) defined resilience as the adaptive capability of a supply chain to get ready for unforeseen events, develop a response to disruptions, and revert to its core structure and function. Tukamuhabwa et al. $(2015$, p. 8) defined resilience as the adaptive capability/capacity of a supply chain to anticipate and react to supply disruptions, recover in a cost effective and efficient manner, and therefore, gravitate to a better state relative to the disruption.

\subsection{Operationalizing Supply Chain Resilience}

Not until some years back that the subject of measuring supply chain resilience came up, Feyzioglu et al. (2007) suggested a systematic measurement/analysis of risky supply chains utilizing Fuzzy cognitive maps. Trucco and Ward (2011) used this measurement in a case study-based research of fast moving consumer goods. However, it is only related to the vulnerabilities in the supply chain, which has little consequence to the resilience framework. Many other researchers focused on exploratory ideas without making any quantitative deductions or statistical inferences. It was not until the year 2008 that Pettit (2008) brought these ideas together to model the measurement dimensions/indicators of supply chain resilience, which involves vulnerability to diverse forms of external and internal hazards or risks and capability to cope within these. Subsequently, numerous studies have used these measurement dimensions. In his findings, capabilities and vulnerabilities are two dimensions/indicators that must be identified when investigating resilience. Thus, an improvement in a supply chain's resilience requires enhancement of capabilities and mitigation of vulnerabilities (Barroso, Machado \& Cruz 2011; Pettit et al., 2011; Aigbogun, Ghazali Razali, 2017).

\subsubsection{Capabilities}

Capabilities enable an organization to anticipate and overcome disruptions (Pettit et al., 2013). Rice and Caniato (2003) identified flexibility, security, redundancy, and knowledge management as 4 major capabilities that impact a supply chain's resilience. Fiksel (2003) identified; diversity, efficiency; adaptability; and cohesion. Christopher and Peck (2004) identified flexibility, agility, and agility (with visibility and velocity as elements) as necessary capabilities to achieve resilience. Sheffi (2005), in his paper "The Resilient Enterprise", points to the fact that for firms to build resilience, they must have capabilities in 3 areas: increasing redundancy, shifting corporate culture, and imbibing flexibility. Pettit (2008) identified 14 capability 
factors as precursors to supply chain resilience. Flexibility, efficiency, organization, anticipation, reserve capacity, visibility, asset dispersion, adaptability, recovery, collaboration, financial strength, market position, and security. Ponomarov and Holcomb (2009) identified 11 capability factors: visibility, collaboration, security, flexibility, reserve capacity, asset dispersion, efficiency, recovery adaptability, organization, anticipation, market position, and financial strength. They also assert that adaptability is a vital capability for building resilience. Blos et al. (2009) identified flexibility and visibility. Blackhurst et al. (2012) identified flexibility, visibility, security, and redundancy, while according to Umang, Soni and Vipul (2011), capabilities are built into the supply chain via flexibility, adaptability, collaboration, and visibility. Furthermore, according to Deloitte (2012), four capabilities are key to building resilient supply chains. They are; visibility, flexibility, collaboration, and control.

\subsubsection{Vulnerabilities}

The large volume of published studies on resilience describes the role of vulnerabilities in managing risky supply chains. Waters (2011) view vulnerability as a system capacity that may limit its capability to withstand threats and survive accidental occurrences. This definition is in unity with the views of Pettit et al. (2011), who define vulnerabilities as vital influences that make a firm prone to disruptions. Therefore, research scholars believe that by addressing the vulnerability of a supply chain, disruptions are mitigated, and hence, the system's resilience is improved (Svensson, 2002; Wagner \& Bode, 2006; Blos et al., 2009).

Pettit (2008), via a semi-structured interview, identified six vulnerabilities in global supply chains. They are turbulence, external pressures, connectivity, sensitivity, deliberate threats, and resource limits. The findings of Fakoor et al. (2013), via a Delphi approach, identified five vulnerabilities of the Iranian automobile industry supply chain. External factors include sourcing and supply limitations, production issues, distribution problems, and poor communication. Ubidia (2014) findings, via a case study approach of global enterprises, revealed seven supply chain vulnerabilities: External pressures, connectivity, sensitivity, supplier/customer disruptions, turbulence, resource limits, and deliberate threats.

\subsection{Supply Chain Orientation}

This is the acknowledgement by a firm of the systematic, strategic consequences of the tactical actions necessary to manage logistics within a supply chain (Min, Mentzer, \& Ladd, 2001). According to Esper et al. (2010), supply chain orientation directly influences organizational performance by developing and sustaining behavioural elements that allow a firm to connect with other stakeholders, which is vital to value creation within an organization. Efficient execution of strategies to build resilience requires the organization to emphasize integration crucial to supply chain management exchange. In essence, supply chain orientation represents a shared value and belief system that aids in understanding how the organization should strategically manage its supply chain and the behavioural norms needed inside the organization (Esper et al., 2010). This suggests that organizations with supply chain orientation approach supply chain resilience differently compared to firms that are less inclined to view supply chain resilience strategically.

\subsection{Collaborative Regulation}

The word "regulate" is derived from the Latin word regulare meaning 'to control', and regula, meaning 'ruler' (Jackson, 1997). The latter has embedded within its notions of ruling and measurement. Thus, regulation enforces requirements using legitimate force on business firms by governments, their agencies, or supranational authorities (OECD, 2010). When regulatory bodies enter into a cooperative, coordinated and joint working relationship with supply chain actors for the common good, it is referred to as collaborative regulation.

Aldrich and Pfeffer (1976) argue that organizations cannot produce all their resources internally; thus, they must form collaborations with other stakeholders. A key external environmental stakeholder that has been given limited attention in the literature is collaborative regulation (Yunus, 2012; Yunus \& Tadisina, 2016). Zhao (2016) views collaborative regulation as synchronized, steady, and strategic activities that include: efficient and consistent harmonization and communications; sharing of knowledge, experience, and resources; exploration of synergies; identification of possible regulatory overlaps; and development of means of collaborative approaches to policy and regulatory control instruments. Thus, in the supply chain management, collaborative regulation involves the joint ability to mitigate supply chain disruptions via collaborative planning with supply chain actors (Christopher, 2016) and information- and intelligence-sharing (Jüttner \& Maklan, 2011) to coordinate the immediate response (Scholten et al., 2014).

\subsection{Agency Theory and Institution Theory}

To comprehend the supply chain setup for the present study, a frame of reference is established. Supply chain management is viewed from multiple principal-agent relationships and an institutional perspective. Therefore, the agency theory and the institutional theory have been applied, as these theories are typically used to identify the best structure for the management of institutions (Fayezi et al., 2012). They are explanatory, and they specify relations among the characteristics of groups, situations, and events in a supply chain when perceived as a collaboration of institutions. 
Charles Perrow's agency theory proposed that agency theory explains the connection between principals and agents in business (Perrow, 1986). From the perspective of agency theory, the supply chain consists of multiple principal-agent relationships whose goal is to deliver value at the interfacing of their activities. As a result, a control mechanism is needed to alleviate the conflicting interests, information asymmetry, and incongruent goals between the principal and the agent. This is where collaborative regulation comes into play. So, when an already established mechanism (e.g. regulatory authority) is embedded into supply chain events, the arrangements (collaborative regulation) devised to monitor these multiple principalagent relationships are themselves agents in these relationships.

Moreover, Institutional theory centers on how external forces (e.g. regulatory authorities) influence organizational actions (DiMaggio \& Powell, 1983). Organizations are faced with pressures to adjust their behaviour per shared notions, for which violations may affect their ability to secure customers and resources (Scott, 2008). Influences that shape social and organizational structures, rules and routines (which all have an outcome in the behaviour of social actors), are part of institutional theory (Scott, 2008). When the three forces of institutional change (mimetic, normative and coercive) are considered analytically, only coercive isomorphism relates directly to the environment surrounding the organizational field (Zsidisin et al., 2005). Mimetic and normative processes are internal to the field and aid the understanding of roles and structures. Thus, when firms are subjected to external coercive regulation control, they will in general incline toward isomorphic change

\section{Conceptual Framework and Hypotheses Development}

\subsection{Conceptual Framework}

The literature postulates that supply chain resilience is a hierarchical and multi-dimensional construct with two primary indicators: vulnerabilities and capabilities. In the present study's context, vulnerabilities have 4 elements, and capabilities have six elements (Aigbogun, Ghazali \& Razali, 2014). Thus, along with the measurement dimensions of supply chain resilience, the conceptual framework posits Supply Chain Orientation (SCO) and Collaborative Regulation (CR) as antecedents of supply chain resilience, with $\mathrm{CR}$ acting as a mediator.

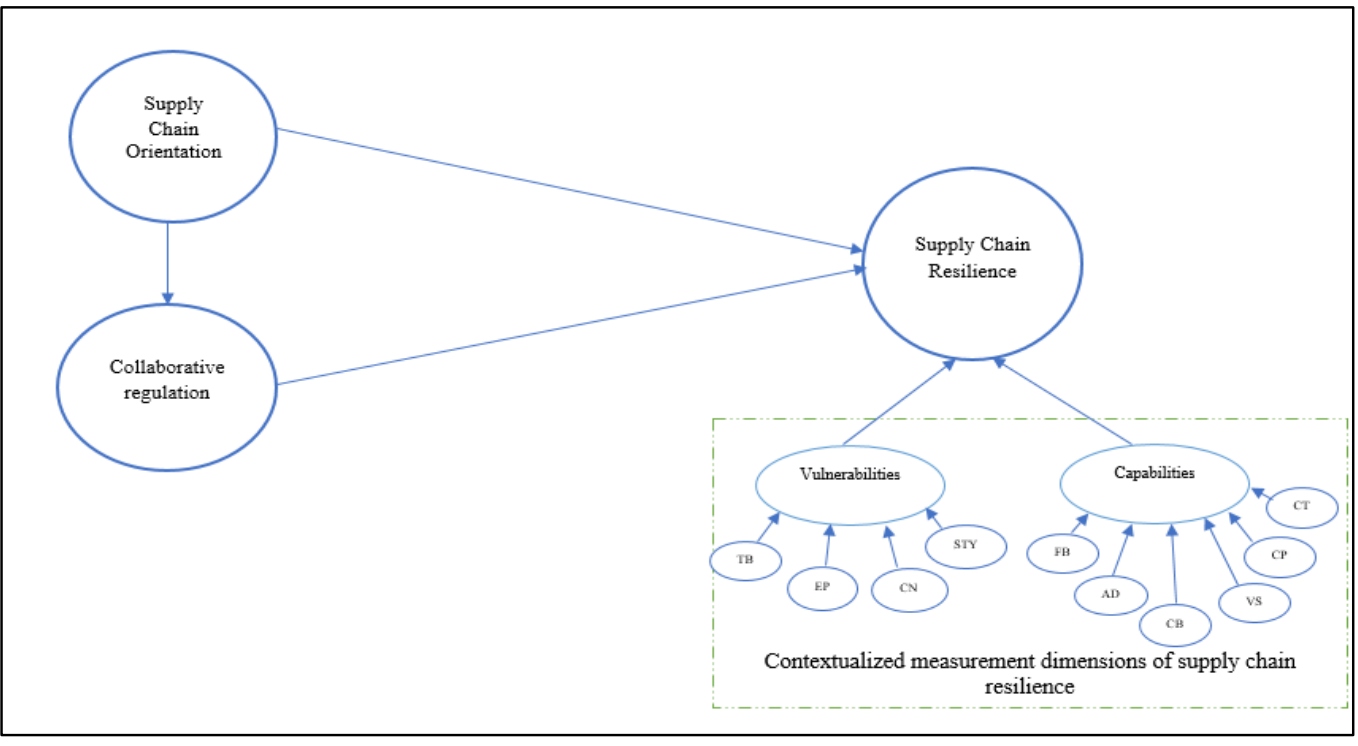

Legend:

Fig. 1. Conceptual Framework

$\mathrm{SCO}=$ Supply chain orientation; $\mathrm{CR}=$ Collaborative regulation; $\mathrm{SCR}$ es $=$ Supply chain resilience; VUL $=\mathrm{Vulnerabilities;}$ $\mathrm{FBY}=$ Flexibility; $\mathrm{CAP}=$ Capabilities; $\mathrm{SD}=$ Supplier dispersion; $\mathrm{TB}=$ Turbulence; $\mathrm{CBN}=\mathrm{Collaboration} \mathrm{EP}=\mathrm{External}$ pressures; CPY= Capacity; STY= Sensitivity; CTY= Connectivity; VBY= Visibility; ADY= Adaptability

\subsection{Hypotheses}

\subsubsection{Supply chain orientation and Supply chain resilience}

Mello and Stank (2005) propose that supply chain-oriented establishments should demonstrate the characteristics of trust, commitment, cooperation, compatibility with stakeholders, and top management support while executing supply chain decisions. This aids the supply chain participants to minimize uncertainty in the network. Jüttner and Maklan (2011) also highlight the significance of trust and open communication in sharing supply chain information and risk information to enhance the resilience of the supply chain. Therefore, the following Hypothesis $\left(\mathrm{H}_{1}\right)$ is put forward: 
$\mathbf{H}_{1}$ : Supply chain orientation positively influences supply chain resilience of pharmaceuticals.

\subsubsection{Collaborative regulation and Supply chain resilience}

From the perspective of agency theory, the supply chain consists of multiple principal-agent relationships, leading to significant conflict of goals between principals and agents (Perrow, 1986; Shapiro, 2005). Due to the conflicts of interests that result from these relationships, a control mechanism is needed. It stands to reason that when an already established mechanism is embedded into supply chain events, the arrangements devised to monitor these multiple principal-agent relationships are agents in these relationships. The findings of Chatterjee and Chaudhuri (2021) show that regulation can act as a governing mechanism to neutralize the asymmetries within the overall supply chain framework. So, the following Hypothesis $\left(\mathrm{H}_{2}\right)$ is put forward:

\section{H2: Collaborative regulation positively influences supply chain resilience of pharmaceuticals.}

\subsubsection{Supply chain orientation, Collaborative regulation and Supply chain resilience}

Features of supply chain orientation such as trust building, co-operation, and strengthening relationships among the supply chain partners are essential for supply chain resilience (Jüttner \& Maklan, 2011; Chowdhury \& Quaddus, 2016). Supply chain resilience is even more accelerated and stronger when collaborative regulation exists in the organizations' industry. The findings of Cao and Zhang (2011), and Deloitte (2012) have shown that collaboration between regulatory authority and supply chain actors confer visibility and flexibility on the supply chain. Thus, industries with collaborative regulation will be very proactive in handling disruptions and conscious of probable risk occurrence in decision-making, making them more resilient. Without collaborative regulatory practices in pharmaceutical manufacturing, the organization's mere attempts at supply chain orientation may not be enough for appropriate risk mitigation. With regards to the above arguments, it can be hypothesized that:

H3: Collaborative regulation mediates the influence of supply chain orientation on supply chain resilience of pharmaceuticals.

\section{Research Methods}

A cross-sectional quantitative method was used to gather primary data using a self-administered structured type of questionnaire. Information regarding the vulnerabilities and capabilities unique to the manufacturing supply chain of pharmaceuticals in Malaysia have been determined in the previous study (Aigbogun, Ghazali, \& Razali, 2014). The unit of analysis is pharmaceutical manufacturing companies in peninsula Malaysia. However, the unit of observation is at the individual level because information about the company's products and operational procedures was gathered from key supply chain executives in each target company. The sample size was calculated to be 102 using the sample size determination formula of Krejcie and Morgan (1970). A stratified random sampling technique was applied. The choice of this technique was because the sampling frame had relevant strata; also, to ensure randomization. The research instrument was a selfadministered structured questionnaire with measures adapted from different studies - Resilience (SCRAM 2.0 $0^{\circ}$ (Pettit et al., 2013); Collaborative Regulation (Chen, Daugherty, \& Roath, 2009); Supply Chain Orientation (Chowdry \& Quaddhus, 2016). To refine the questionnaire, it was subjected to content validity by academic and industry experts and a pilot study for testing internal reliability utilizing Cronbach alpha.

The data analysis was carried out using Statistical Package for Social Sciences (SPSS version 22.0) and Partial Least Squares technique as a part of Structural Equation Modelling (PLS-SEM). The choice of PLS-SEM is because it is highly suitable for testing and validating exploratory research models and is considered a powerful tool for prediction-oriented research (Henseler et al., 2009). Also, partial least squares pose no restrictive assumptions of multivariate normality that covariancebased structural equation modelling confines (Hair et al., 2016). Management of response data and descriptive statistics were carried out using SPSS. However, to test the research hypotheses, PLS-SEM was used to analyze the causal relationships between variables using the Smart PLS 3.2.1 software. The dependent variable, supply chain resilience, was modelled as a higher-order hierarchical model of the measurement indicators in formative mode. Based on previous studies on supply chain resilience (Jüttner \& Maklan, 2011; Chowdhury \& Quaddus, 2016), formative measurement mode has been selected for measuring the indicators of supply chain resilience, and reflective mode for the antecedents. To estimate the higher-order construct of supply chain resilience, a two-stage approach for simplification of the model was applied (Becker et al., 2012). As the supply chain resilience measurement constructs were operationalized in the formative mode, the measurement aspect of the supply chain resilience model was analyzed by examining indicator weight, loading, and variance inflation factor (Hair et al., 2011).

On the other hand, Supply Chain Orientation and Collaborative Regulation, being reflective measures, were examined by evaluating the item reliability, internal consistency, average variance extracted (AVE) and discriminant validity (Hair et al., 2011). The structural model was evaluated by analyzing the explanatory power of endogenous constructs and examining the $\mathrm{t}$-values of each path coefficient corresponding to the hypotheses. It is noteworthy that non-parametric bootstrapping was also applied with 1,000 replications to obtain the standard errors of the estimates. Approval for the study protocol was obtained from the Ethics Research Committee of Binary University of Management and Entrepreneurship, Malaysia. 


\section{Analysis and Findings}

\subsection{Assessment of the Measurement Model (Model Reliability)}

\subsubsection{Formative constructs}

Each item measure of the first order formative supply chain resilience construct was evaluated for its outer weights and loadings. Among the original 48 items, 43 had significant weights and loadings above the recommended minimum threshold values. The remaining 5 items (V1.2, V3.3, V3.6, C2.1, and C4.1) that had insignificant weights and loadings were deleted from the model (Hair et al., 2011). Also, collinearity was evaluated by examining Variance Inflation Factor (VIF) values. The bootstrapping results of the trimmed supply chain resilience measurement model at first-order level show that the indicator item weights and loadings were significant $(t>1.96 ; \mathrm{p}>0.05)$. Three outer weights for three indicators (V2.4, V3.4 and V4.5) were not significant; however, their loadings were greater than 0.5 and significant, and as a result they were retained in the model (Hair et al., 2016). The bootstrapping results of the formative second-order constructs (Table 2) and higher-order constructs (Table 3 ) show significant indicator weights and loadings $(t>1.96 ; p>0.05)$ for all the indicators.

Table 1

Resilience measurement model at first-order level

\begin{tabular}{|c|c|c|c|c|c|c|c|c|}
\hline \multirow{2}{*}{ 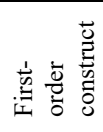 } & \multirow[t]{2}{*}{ Items } & \multicolumn{3}{|l|}{ Weights } & \multicolumn{3}{|c|}{ Loadings } & \multirow{2}{*}{ VIF } \\
\hline & & $w$ & $\begin{array}{c}t- \\
\text { value }\end{array}$ & $p$-value & $l$ & $\begin{array}{c}t- \\
\text { value }\end{array}$ & $p$-value & \\
\hline \multirow{5}{*}{ TB } & V1.1- Cust. demand unpredictability & 0.484 & 2.852 & 0.004 & 0.851 & 2.720 & 0.005 & 2.032 \\
\hline & V1.2- Sup. currency/price fluctuation* & & & & & & & \\
\hline & V1.3- Supplier geopolitical disruptions & 0.641 & 8.213 & 0.000 & 0.761 & 2.126 & 0.028 & 2.390 \\
\hline & V1.4- Exposure to natural disasters & 0.496 & 4.115 & 0.000 & 0.812 & 4.185 & 0.000 & 2.177 \\
\hline & V1.5- Unforeseen technology failures & 0.364 & 2.951 & 0.001 & 0.918 & 3.038 & 0.000 & 1.957 \\
\hline \multirow{4}{*}{ EP } & V2.1- Competitive innovation & 0.567 & 8.625 & 0.000 & 0.911 & 2.580 & 0.007 & 1.563 \\
\hline & V2.2- Price pressures & 0.635 & 4.682 & 0.000 & 0.961 & 2.705 & 0.006 & 2.824 \\
\hline & V2.3-Corporate responsibility & 0.184 & 4.462 & 0.000 & 0.691 & 2.836 & 0.004 & 2.661 \\
\hline & V2.4- Social/Cultural issues & 0.316 & 1.796 & 0.063 & 0.784 & 2.892 & 0.002 & 1.752 \\
\hline \multirow{7}{*}{ STY } & V3.1- Presence of restricted materials & 0.179 & 6.913 & 0.000 & 0.711 & 4.119 & 0.000 & 1.023 \\
\hline & V3.2- Importance of supply purity & 0.237 & 3.872 & 0.000 & 0.782 & 9.065 & 0.000 & 2.805 \\
\hline & V3.3- Stringency of manufacturing* & & & & & & & \\
\hline & V3.4- Fragility of handling & 0.120 & 0.901 & 0.089 & 0.898 & 4.903 & 0.000 & 2.378 \\
\hline & V3.5-Stakeholder visibility & 0.365 & 22.213 & 0.000 & 0.880 & 19.237 & 0.000 & 2.171 \\
\hline & V3.6- Symbolic profile of brand* & & & & & & & \\
\hline & V3.7- Customer quality requirement & 0.483 & 13.326 & 0.000 & 0.854 & 8.457 & 0.000 & 1.917 \\
\hline \multirow{6}{*}{ CTY } & V4.1- Scale of supply network & 0.206 & 2.213 & 0.027 & 0.869 & 7.751 & 0.000 & 1.638 \\
\hline & V4.2- Extent of supply network & 0.214 & 3.336 & 0.000 & 0.637 & 2.050 & 0.031 & 1.774 \\
\hline & V4.3- Reliance upon specialty sources & 0.217 & 11.110 & 0.000 & 0.949 & 2.892 & 0.002 & 1.741 \\
\hline & V4.4- Reliance upon information flow & 0.209 & 5.129 & 0.000 & 0.632 & 2.851 & 0.003 & 1.606 \\
\hline & V4.5- Degree of outsourcing products & 0.234 & 1.694 & 0.069 & 0.718 & 4.859 & 0.000 & 2.211 \\
\hline & V4.6- Degree of outsourcing package & 0.233 & 3.261 & 0.000 & 0.664 & 4.985 & 0.000 & 2.161 \\
\hline \multirow{5}{*}{ FBY } & C1.1- Common product platforms & 0.536 & 3.693 & 0.000 & 0.851 & 2.631 & 0.007 & 2.193 \\
\hline & C1.2- Supply contract flexibility & 0.445 & 6.102 & 0.000 & 0.796 & 21.666 & 0.000 & 1.928 \\
\hline & C1.3- Supplier capacity & 0.303 & 2.998 & 0.001 & 0.685 & 19.164 & 0.000 & 1.434 \\
\hline & C1.4- Supplier expediting & 0.337 & 9.613 & 0.000 & 0.750 & 2.948 & 0.001 & 2.984 \\
\hline & C1.5-Alternate suppliers & 0.149 & 2.343 & 0.021 & 0.779 & 15.964 & 0.000 & 3.327 \\
\hline \multirow{5}{*}{ VBY } & C2.1- Information technology* & & & & & & & \\
\hline & C2.2- Status of inventory & 0.297 & 2.871 & 0.002 & 0.715 & 14.371 & 0.000 & 2.355 \\
\hline & C2.3- Status of personnel & 0.605 & 4.216 & 0.000 & 0.932 & 35.804 & 0.000 & 3.799 \\
\hline & C2.4- Information exch. with suppliers & 0.239 & 6.128 & 0.000 & 0.905 & 34.062 & 0.000 & 3.018 \\
\hline & C2.5- External monitoring & 0.386 & 5.113 & 0.000 & 0.711 & 5.112 & 0.000 & 3.347 \\
\hline \multirow{4}{*}{$\mathrm{CBN}$} & C3.1- Supply chain communication & 0.171 & 2.222 & 0.028 & 0.854 & 24.719 & 0.000 & 2.935 \\
\hline & C3.2- Sup. involvement in innovation & 0.413 & 5.842 & 0.000 & 0.909 & 43.599 & 0.000 & 2.982 \\
\hline & C3.3-Postponement of orders & 0.517 & 7.101 & 0.000 & 0.924 & 41.312 & 0.000 & 2.176 \\
\hline & C3.4- Supplier collaboration & 0.565 & 19.828 & 0.000 & 0.654 & 5.190 & 0.000 & 1.117 \\
\hline \multirow{4}{*}{ ADY } & C4.1-Seizing advantage from disruptions* & & & & & & & \\
\hline & C4.2- Alternative technology & 0.455 & 15.392 & 0.000 & 0.740 & 31.111 & 0.000 & 2.681 \\
\hline & C4.3- Strategic techniques & 0.157 & 2.040 & 0.032 & 0.917 & 26.069 & 0.000 & 2.793 \\
\hline & C4.4- Environmental sustainability & 0.335 & 3.981 & 0.000 & 0.685 & 20.057 & 0.000 & 2.568 \\
\hline \multirow{4}{*}{ CPY } & C5.1- Backup utilities & 0.706 & 1.976 & 0.042 & 0.650 & 15.908 & 0.000 & 2.552 \\
\hline & C5.2- Raw materials & 0.707 & 3.687 & 0.000 & 0.935 & 2.246 & 0.025 & 2.918 \\
\hline & C5.3- Reserve capacity & 0.421 & 4.582 & 0.000 & 0.806 & 1.976 & 0.043 & 3.486 \\
\hline & C5.4- Labor capacity & 0.340 & 1.991 & 0.039 & 0.718 & 1.968 & 0.047 & 3.155 \\
\hline \multirow{4}{*}{ SD } & C6.1- Distributed suppliers & 0.407 & 6.710 & 0.000 & 0.755 & 18.139 & 0.000 & 1.323 \\
\hline & C6.2- Distributed production & 0.367 & 4.723 & 0.000 & 0.841 & 23.431 & 0.000 & 1.975 \\
\hline & C6.3- Dispersed distribution & 0.249 & 2.918 & 0.001 & 0.833 & 25.686 & 0.000 & 2.771 \\
\hline & C6.4- Distributed raw materials & 0.257 & 3.250 & 0.000 & 0.796 & 21.123 & 0.000 & 2.605 \\
\hline
\end{tabular}

Note: * Items with low loadings and weights were dropped 
Table 2

Resilience measurement model at second-order level

\begin{tabular}{|c|c|c|c|c|c|c|c|}
\hline \multirow{2}{*}{$\begin{array}{l}\text { Second order Formative } \\
\text { constructs }\end{array}$} & \multirow{2}{*}{$\begin{array}{c}\text { First order } \\
\text { formative constructs }\end{array}$} & \multicolumn{3}{|c|}{ Weights } & \multicolumn{3}{|c|}{ Loadings } \\
\hline & & $w$ & $t$-value & $p$-value & $l$ & $t$-value & $p$-value \\
\hline \multirow{4}{*}{ Vulnerabilities } & TB & 0.589 & 2.827 & 0.004 & 0.741 & 2.521 & 0.008 \\
\hline & EP & 0.588 & 4.905 & 0.000 & 0.859 & 4.309 & 0.000 \\
\hline & STY & 0.319 & 2.449 & 0.011 & 0.795 & 2.067 & 0.029 \\
\hline & CTY & 0.478 & 2.951 & 0.001 & 0.554 & 5.868 & 0.001 \\
\hline \multirow{6}{*}{ Capabilities } & FBY & 0.492 & 4.173 & 0.000 & 0.791 & 5.309 & 0.000 \\
\hline & VBY & 0.367 & 3.681 & 0.000 & 0.670 & 3.113 & 0.000 \\
\hline & $\mathrm{CBN}$ & 0.685 & 7.494 & 0.000 & 0.881 & 2.912 & 0.001 \\
\hline & ADY & 0.346 & 3.974 & 0.000 & 0.692 & 7.118 & 0.000 \\
\hline & CPY & 0.338 & 1.971 & 0.044 & 0.553 & 4.901 & 0.000 \\
\hline & SD & 0.362 & 2.117 & 0.000 & 0.614 & 9.137 & 0.000 \\
\hline
\end{tabular}

Table 3

Resilience measurement model at higher-order level

\begin{tabular}{|c|c|c|c|c|c|c|c|}
\hline Higher-order construct & Second order formative & Weights & & & adings & & \\
\hline \multirow{3}{*}{ Supply Chain Resilience } & & $w$ & $t$-value & p-value & $l$ & $t$-value & $p$-value \\
\hline & Capabilities & 0.586 & 7.434 & 0.000 & 0.837 & 18.223 & 0.000 \\
\hline & Vulnerabilities & 0.494 & 6.162 & 0.000 & 0.762 & 11.134 & 0.000 \\
\hline
\end{tabular}

\subsubsection{Reflective constructs}

Reliability of the reflective measurement model was subjected to internal consistency reliability testing using Cronbach's alpha and Fornell's composite reliability (Hair et al., 2016). The results show reliability scores above the recommended 0.6 thresholds (Table 4), thus affirming the reliability of reflective measures.

Table 4

Reliability results for reflective measurement model

\begin{tabular}{lll}
\hline Construct & Cronbach's Alpha & Composite Reliability \\
\hline Supply Chain Orientation (SCO) & 0.823 & 0.884 \\
Collaborative Regulation (CR) & 0.876 & 0.904 \\
\hline
\end{tabular}

\subsection{Construct Validation}

\subsubsection{Assessing Convergent Validity}

Convergent validity was evaluated by examining the AVE and indicators' outer loadings (Hair et al., 2011). The results (Table 5) reveal that all the constructs exhibited AVE values greater than 0.5, the recommended threshold. This means that the constructs accounted for at least $50 \%$ of measurement variance (Fornell \& Larcker, 1981). Also, the results from the outer loadings (Table 6) were above the accepted critical threshold of 0.70 , except one (CR1.6) that had a loading of 0.694 , which is slightly below 0.7. However, this item was not dropped due to strong justifications from research scholars (Götz et al., 2010; Latan \& Ghozali, 2012a; Latan \& Ramli, 2013).

\section{Table 5}

AVE for reflective constructs

\begin{tabular}{ll}
\hline Construct & AVE \\
\hline Supply Chain Orientation (SCO) & 0.659 \\
Collaborative Regulation (CR) & 0.573 \\
\hline
\end{tabular}

Table 6

Overview of outer loadings of the reflective measures

\begin{tabular}{|c|c|c|c|c|c|}
\hline & $\begin{array}{l}\text { Original Sample } \\
\text { (O) }\end{array}$ & $\begin{array}{l}\text { Sample Mean } \\
\text { (M) }\end{array}$ & $\begin{array}{c}\text { Standard } \\
\text { Deviation } \\
\text { (STDEV) }\end{array}$ & $\begin{array}{l}\text { T Statistics } \\
(|\mathrm{O} / \mathrm{STDEV}|)\end{array}$ & P-Value \\
\hline $\mathrm{SCO} 1 \leftarrow \mathrm{SCO}$ & 0.674 & 0.671 & 0.042 & 15.957 & 0.000 \\
\hline $\mathrm{SCO} 2 \leftarrow \mathrm{SCO}$ & 0.859 & 0.858 & 0.019 & 45.869 & 0.000 \\
\hline $\mathrm{SCO} 3 \leftarrow \mathrm{SCO}$ & 0.888 & 0.888 & 0.012 & 75.590 & 0.000 \\
\hline $\mathrm{SCO} 4 \leftarrow \mathrm{SCO}$ & 0.809 & 0.810 & 0.017 & 47.100 & 0.000 \\
\hline $\mathrm{CR} 1.1 \leftarrow \mathrm{CR}$ & 0.754 & 0.753 & 0.026 & 28.708 & 0.000 \\
\hline $\mathrm{CR} 1.2 \leftarrow \mathrm{CR}$ & 0.786 & 0.786 & 0.026 & 29.723 & 0.000 \\
\hline CR $1.3 \leftarrow$ CR & 0.753 & 0.754 & 0.021 & 36.009 & 0.000 \\
\hline CR $1.4 \leftarrow \mathrm{CR}$ & 0.710 & 0.709 & 0.031 & 22.989 & 0.000 \\
\hline CR $1.5 \leftarrow C R$ & 0.805 & 0.806 & 0.020 & 39.824 & 0.000 \\
\hline CR $1.6 \leftarrow \mathrm{CR}$ & 0.694 & 0.694 & 0.034 & 20.608 & 0.000 \\
\hline CR $1.7 \leftarrow \mathrm{CR}$ & 0.791 & 0.791 & 0.024 & 33.368 & 0.000 \\
\hline
\end{tabular}




\subsubsection{Assessing Discriminant Validity (Fornell-Larcker Criterion)}

Examining the constructs loadings indicated that all the measurement items loaded more on their latent construct than on other constructs. The construct loading values were greater than the cross-loading values, thus affirming discriminant validity (Hair et al., 2017).

\subsection{Assessment of the Structural Model}

In evaluating the structural model, the path estimates, coefficients of determination $\left(\mathrm{R}^{2}\right)$, effect sizes $\left(f^{2}\right)$, predictive relevance $\left(\mathrm{Q}^{2}\right)$ and Goodness of Fit (GoF) were evaluated (Hair et al., 2017).

\subsubsection{Path Estimates (Direct Effect Relationships: $H_{1}$ and $H_{2}$ )}

The path weighing scheme was applied to test the direct effect relationships that address two research hypotheses $\left(\mathrm{H}_{1}\right.$ and $\mathrm{H}_{2}$ ). The results (Table 7) indicate that Supply Chain Orientation (SCO) positively influences supply chain resilience (SCRes) as was hypothesized $\left(\mathrm{H}_{1}: \beta=0.341, \mathrm{p}<0.001\right.$, LL: 0.205, UL: 0.456). Also, Collaborative Regulation (CR) positively influences supply chain resilience (SCRes) as was hypothesized $\left(\mathrm{H}_{2}: \beta=0.506, \mathrm{p}<0.001\right.$, LL: 0.434, UL: 0.578).

\section{Table 7}

Results of direct effect relationships

\begin{tabular}{|c|c|c|c|c|c|c|c|}
\hline \multirow[t]{2}{*}{ Hypotheses } & \multirow[t]{2}{*}{ Path } & \multirow{2}{*}{$\begin{array}{c}\text { Path } \\
\text { coefficient } \\
\beta\end{array}$} & \multirow[t]{2}{*}{$t$-value } & \multirow[t]{2}{*}{$p$-value } & \multicolumn{2}{|c|}{$\begin{array}{l}\text { Confidence Intervals Bias } \\
\text { corrected }\end{array}$} & \multirow[t]{2}{*}{ Decision } \\
\hline & & & & & $(\mathrm{LL})(2.5 \%)$ & (UL) $(97.5 \%)$ & \\
\hline $\mathrm{H}_{1}$ & $\mathrm{SCO} \rightarrow$ SCRes $(+)$ & 0.341 & 5.352 & 0.000 & 0.205 & 0.456 & Supported \\
\hline $\mathrm{H}_{2}$ & $\mathrm{CR} \rightarrow$ SCRes $(+)$ & 0.506 & 13.790 & 0.000 & 0.434 & 0.578 & Supported \\
\hline
\end{tabular}

\subsubsection{Path Estimates (Indirect Effect Relationship: $H_{3}$ )}

The indirect effect is formulated as the difference between the total and direct effect (Indirect effect $=$ Total effect - Direct effect). Thus, in carrying out the mediation analysis, an underlying theoretical and practical support advocated by Preacher and Hayes $(2004,2008)$ for mediation analysis was utilized in the present study. As such, the advanced procedure typology for mediation analysis in PLS mediation, with a decision tree as guideline factoring the characteristics of PLS into consideration was followed. The results of indirect effect at $95 \%$ confidence interval bias corrected (Table 8) shows that CR mediates the path relationship ( $\mathrm{SCO} \rightarrow \mathrm{CR} \rightarrow \mathrm{SCRes}$ ) between $\mathrm{SCO}$ and SCRes $\left(\mathrm{H}_{3}: \beta=0.336, \mathrm{p}<0.001, \mathrm{LL}: 0.013, \mathrm{UL}\right.$ : 0.271). The relationship between SCO and SCRes, which was significant in the direct relationship $\left(\mathrm{H}_{1}\right)$, was still significant in the indirect relationship, thus revealing a partial mediation.

Table 8

Results of indirect relationship (mediation analysis)

\begin{tabular}{|c|c|c|c|c|c|c|c|}
\hline \multirow[t]{2}{*}{ Hypotheses } & \multirow[b]{2}{*}{ Path } & \multirow[b]{2}{*}{$\begin{array}{l}\text { Path } \\
\text { Coefficient } \beta\end{array}$} & \multirow[b]{2}{*}{$t$-value } & \multirow[b]{2}{*}{$p$-value } & \multicolumn{2}{|c|}{ Confidence Intervals Bias corrected } & \multirow[b]{2}{*}{ Decision } \\
\hline & & & & & $(\mathrm{LL})(2.5 \%)$ & (UL) $(97.5 \%)$ & \\
\hline $\mathrm{H}_{3}$ & $\mathrm{SCO} \rightarrow \mathrm{CR} \rightarrow$ SCRes & 0.336 & 4.215 & 0.000 & 0.013 & 0.271 & Supported \\
\hline
\end{tabular}

\subsubsection{Coefficient of Determination $\left(R^{2}\right)$}

As illustrated in Table 9, the $\mathrm{R}^{2}$ value of 0.339 suggests that the two exogenous constructs (SCO and CR) can jointly explain $33.9 \%$ of the variance of the endogenous construct (SCRes), which is significant at the $95 \%$ level of confidence $(\mathrm{t}-\mathrm{value}=$ $12.919 ; \mathrm{p}$-value $=0.000)$. Furthermore, the same model estimation also reveals the $\mathrm{R}^{2}(0.174)$ for SCO is found to explain $17.4 \%$ of the variance in CR which is significant at the $95 \%$ level of confidence ( $t$-value $=20.080 ; p$-value $=0.000$ ).

\section{Table 9}

Coefficient of determination $\left(\mathrm{R}^{2}\right)$

\begin{tabular}{llll} 
& & T-statistics & $\mathrm{p}$-value \\
\hline Supply chain resilience & $\mathrm{R}^{2}$ & 12.919 & 0.000 \\
Collaborative regulation & 0.339 & 20.080 & 0.000 \\
\hline
\end{tabular}

\subsubsection{Effect Size $\left(f^{2}\right)$}

This test was carried out to assess the effect of a specific exogenous construct on the endogenous construct if it is deleted from the model. According to Cohen (1988), the following are the guidelines for assessing $f^{2}$ : 
$-0.02 \rightarrow$ small

$-0.15 \rightarrow$ medium

$-0.35 \rightarrow$ large effects

As illustrated in Table 10 the result of $f^{2}$ effect sizes shows that CR has a large effect $(0.35)$ on explaining the $\mathrm{R}^{2}$ of SCRes. Also, SCO has a large effect $(0.38)$ on the explanation of the $\mathrm{R}^{2}$ of SCRes. SCO (0.27) has a medium effect on explaining the $\mathrm{R}^{2}$ of $\mathrm{CR}$.

Table 10

Result of $f^{2}$ effect sizes

\begin{tabular}{lllll}
\hline & $f^{2}$ Effect Size & t-value & p-value & Interpretation of effect size \\
\hline $\mathrm{SCO} \rightarrow$ SCRes & 0.38 & 2.281 & 0.023 & large \\
$\mathrm{CR} \rightarrow$ SCRes & 0.35 & 4.700 & 0.000 & large \\
$\mathrm{SCO} \rightarrow \mathrm{CR}$ & 0.27 & 3.956 & 0.000 & medium \\
\hline
\end{tabular}

\subsubsection{Predictive Relevance $\left(Q^{2}\right)$ and Goodness of Fit of the Model (GoF)}

Through blindfolding processes, Stone-Geisser test was used to determine the model's predictive relevance (Stone, 1974). The results revealed a $\mathrm{Q}^{2}$ statistic of 0.49 and 0.561 for the endogenous latent variables (supply chain resilience and collaborative regulation). The $\mathrm{Q}^{2}$ outputs are greater than zero thus verifying the model's predictive relevance (Jain, Vyas, \& Chalasani, 2016).

The GoF values were 0.702 and 0.795 for (supply chain resilience and collaborative regulation), respectively, surpassing the critical threshold value of 0.36 (Wetzels et al., 2009). As a result, it can be affirmed that the GoF model of this study is sufficient to consider satisfactory PLS model validity.

\section{Discussion and Conclusion}

The findings from this study indicate that supply chain orientation is required for enhancing supply chain resilience. This finding is in tandem with previous study of Adobor (2019) who affirm that the higher the supply chain orientation, the higher the supply chain resilience. More specifically, enhancement of supply chain orientation in the form of top management support, improving trust, cooperation and commitment among supply chain partners leads to reduction of risk arising from supply chain vulnerabilities, resulting in supply chain resilience.

Further, the result of this study indicates that collaborative regulations have a positive influence on supply chain resilience. This finding is aligned with previous studies (Mehralian, Moosivand, Emadi, Asgharian, 2017; Chatterjee \& Chaudhuri, 2021). The enhancement of collaborative regulation in the form of process connection and process simplicity leads to mitigation of risk arising from supply chain vulnerabilities, thus improving supply chain resilience.

Further, the findings of this study show that collaborative regulation significantly mediates the link between supply chain orientation and supply chain resilience, which is supported by past study (Deloitte, 2012). When organizations are exposed to external coercive regulatory control, they will generally incline toward positive isomorphic change. The outcomes of this study point out that this positive isomorphic transformation appears as a significant element of resilient supply chains. The role of collaborative regulation as a complementary mediator embodies a process that embeds collaborative approaches for improved resilience of the supply chain employing coordinated, consistent, and strategic activities that include: effective and regular coordination and interactions; and development of collaborative approaches to policy implementation, joint working relationships with supply chain actors, and regulatory control mechanisms.

\subsection{Practical Implication}

Arising from the numerous COVID-19 induced supply chain disruptions, and despite possessing distinct cultures, the member nations of ASEAN are positioning themselves for speedy and sustainable regional economic growth. The findings from this study show that the member states must leverage on its closer ties with China by empowering supranational regulatory bodies. This is key in building resilient supply chain systems, as this will be a key enabler for business continuity and survival of many domestic businesses to launch into larger markets through cross-border China-ASEAN trade cooperation successfully.

\subsection{Theoretical Implication}

By applying the tenets of agency theory, as well as the institutional theory, and expanding it to a broader base with contextual modification, a background is laid for other researchers to apply this knowledge in future research on supply chain resilience. This thus adds to the repository of knowledge on agency theory in developing the required level of capabilities, and mitigation 
of vulnerabilities, via the intermediary role of collaborative regulation. The hierarchical supply chain resilience model applied in the present research, lays a solid theoretical foundation for future research on supply chain resilience.

\subsection{Future direction and Conclusion}

The current study investigated the relationship between supply chain orientation, collaborative regulations and supply chain resilience and found a positive relationship among them. This study shows the importance of the right supply chain orientation, which would enable supply chain resilience, especially during the COVID-19 pandemic. Future researchers can take a cue from this study and concentrate research efforts on developing a China-ASEAN supply chain collaboration model in the field of supply security and supranational regulatory collaboration for boosting visibility, sustainability and business continuity. Further, future studies may investigate supply chain resilience in other industries such as agriculture and automobiles.

\section{References}

Aigbogun, O., Ghazali, Z., \& Razali, R. (2014). A framework to enhance supply chain resilience the case of Malaysian pharmaceutical industry. Global Business and Management Research, 6(3), 219.

Aigbogun, O., Ghazali, Z., \& Razali, R. (2018). Collaborative Regulation and Supply Chain Resilience: A Conceptual Paper. In SHS Web of Conferences (Vol. 56, p. 05002). EDP Sciences.

Aigbogun, O., Ghazali, Z., \& Razali, R. (2017). The Impact of Regulatory Function on Supply Chain Resilience: Reliability of Measurement Scales. Global Business and Management Research: An International Journal, 9(1s), 524-531

Adobor, H. (2019). Supply chain resilience: a multi-level framework. International Journal of Logistics Research and Applications, 22(6), 533-556.

Aldrich, H. E. \& Pfeffer, J. (1976). Environments of organizations. Annual Review of Sociology, 2, 79-105.

Barroso, A. P., Machado, V. C., \& Machado, V. H. (2011). Supply chain resilience using the mapping approach. InTech Open Access Publisher.

Becker, J.M., Klein, K. \& Wetzels, M. (2012). Hierarchical latent variable models in PLS-SEM: guidelines for using reflective-formative type models. Long Range Planning, 45(5), 359-394.

Blackhurst, J., Craighead, C.W., Elkins, D. \& Handfield, R.B. (2005). An empirically derived agenda of critical research issues for managing supply-chain disruptions. International Journal of Production Research, 43(19), 4067-4081.

Blos, M. F., Wee, H. M., \& Yang, W. H. (2012). Supply chain risk management: resilience and business continuity. In Handbook on decision making (pp. 219-236). Springer, Berlin, Heidelberg.

Burger, K., \& Warner, J. (2012). Risk Governance of Food Supply Chains. International risk governance council (IRGC) as part of project work on public sector governance of emerging risks.

Burtles, J. (2016). Principles and Practice of Business Continuity: Tools and Techniques Second Edition. Rothstein Publishing.

Cao, M., \& Zhang, Q. (2011). Supply chain collaboration: Impact on collaborative advantage and firm performance. Journal of Operations Management, 29(3), 163-180.

Chatterjee, S., \& Chaudhuri, R. (2021). Supply chain sustainability during turbulent environment: Examining the role of firm capabilities and government regulation. Operations Management Research, 1-15.

Chen, H., Daugherty, P. J., \& Roath, A. S. (2009). Defining and operationalizing supply chain process integration. Journal of Business Logistics, 30(1), 63-84.

Chowdhury, M.M.H. \& Quaddus, M.A. (2016). Supply chain readiness, response and recovery for resilience. Supply Chain Management: An International Journal, 21(6), 709-731.

Christopher, M. \& Peck, H. (2004). Building the resilient supply chain. International Journal of Logistics Management, 15(2), 1-13.

Christopher, M. (2016). Logistics \& supply chain management. Pearson UK.

Cohen, J. (1988). Statistical Power Analysis for the Behavioral Sciences, Lawrence Erlbaum Associates, Hillsdale, NJ.

Cohen, J., \& Cohen, P. (1983). Applied multiple regression/correlation analysis for the behavioral sciences. Hillsdale, NJ: Lawrence Erlbaum Associates, Inc.

Deloitte. Supply Chain Resilience (2012). A Risk Intelligent approach to managing global supply chains. White paper, 2012, http://www.deloitte.com/assets/DcomUnitedStates/Local\%20Assets/Documents/us_consulting_supplychainresilience_0 52312.pdf (Accessed 25 Nov 2020).

DiMaggio, J., \& Powell, W. (1983). The iron cage revisited: institutional isomorphism and collective rationality in organizational fields. American Sociological Review, 48, 147-60.

Esper, T.L., Defee, C.C. \& Mentzer, J.T. (2010). A framework of supply chain orientation. International Journal of Logistics Management, 21(2), 161-179.

Fakoor, A. M., Olfat, L., Feizi, K., \& Amiri, M. (2013). A method for measuring supply chain resilience in the automobile industry. Journal of Basic and Applied Scientific Research, 3(2), 537-544

Fayezi, S., O'Loughlin, A., \& Zutshi, A. (2012). Agency theory and supply chain management: a structured literature review. Supply Chain Management: An International Journal, 17(5), 556-570 
Feyzioglu, O., Buyukozkan, G., \& Ersoy, M. S. (2007, December). Supply chain risk analysis with fuzzy cognitive maps. In Industrial Engineering and Engineering Management, 2007 IEEE International Conference on (pp. 1447-1451). IEEE.

Fiksel, J. (2003). Designing resilient, sustainable systems. Environmental Science \& Technology, 37(23), 5330-5339.

Fornell, C. \& Larcker, D.F. (1981). Evaluating structural equations models with unobservable variables and measurement error. Journal of Marketing Research, 18(1), 39-50.

Gölgeci, I. \& Ponomarov, S.Y. (2015). How does firm innovativeness enable supply chain resilience? The moderating role of supply uncertainty and interdependence. Technology Analysis \& Strategic Management, 27(3), 267-282.

Gotz, O., Liehr-Gobbers, K., \& Krafft, M. (2010). Evaluation of Structural Equation Models Using the Partial Least Partial Least Squares (PLS) Approach. In V.E. Vinzi, W. W. Chin, J. Henseler, \& H. Wang (Eds.), Handbook of partial least squares: Concepts, methods and applications in marketing and related fields (pp. 691-711). Berlin: Springer.

Hair, J., Hult, T., Ringle, C. \& Sarstedt, M., (2017). A Primer on Partial Least Squares Structural Equation Modeling (PLSSEM). [online] Available at: http://hdl.handle.net/11420/4083

Hair, J.F., Hult, G.T.M., Ringle, C.M. \& Sarstedt, M. (2016). A Primer on Partial Least Squares Structural Equation Modeling (PLS-SEM). Sage, Thousand Oaks, CA.

Hair, J.F., Ringle, C.M. \& Sarstedt, M. (2011). PLS-SEM: Indeed a silver bullet. The Journal of Marketing Theory and Practice, 19(2), 139-152.

Henseler, J., Ringle, C. \& Sinkovics, R. (2009). The use of partial least squares path modeling in international marketing. Advances in International Marketing (AIM), 20(1), 277-320.

Jackson, N. (1997). Academic regulation in UK higher education: part I - the concept of collaborative regulation. Quality Assurance in Education, 5(3), 120 - 135

Jain, P., Vyas, V. \& Chalasani, D. P. S. (2016). Corporate social responsibility and financial performance in SMEs: A structural equation modelling approach. Global Business Review, [e-journal] 17(3), 630-53. https://doi. org/10.1177/0972150916630827

Jüttner, U. \& Maklan, S. (2011). Supply chain resilience in the global financial crisis: an empirical study. Supply Chain Management: An International Journal, 16(4), 246-259.

Krejcie, R. V., \& Morgan, D. W. (1970). Determining sample size for research activities. Educ psychol meas.

Latan, H., \& Ghozali, I. (2012a). Partial Least Squares: Concept, Technique and Application SmartPLS 2.0 M3, Badan Penerbit Universitas Diponegoro, Semarang.

Latan, H., \& Ghozali, I. (2012b). Partial Least Squares: Concept, Metode and Application WarpPLS for Empirical Research, Badan Penerbit Universitas Diponegoro, Semarang.

Latan, H., \& Ramli, N. A. (2013). The Results of Partial Least Squares-Structural Equation Modelling Analyses (PLS-SEM).

Li, G., Fan, H., Lee, P. K., \& Cheng, T. C. E. (2015). Joint supply chain risk management: an agency and collaboration perspective. International Journal of Production Economics, 164, 83-94.

Mello, J. E., \& Stank, T. P. (2005). Linking firm culture and orientation to supply chain success. International Journal of Physical Distribution \& Logistics Management, 35(8), 542-554.

Mehralian, G., Moosivand, A., Emadi, S., \& Asgharian, R. (2017). Developing a coordination framework for pharmaceutical supply chain: using analytical hierarchy process. International Journal of Logistics System Management, $26(3), 277-93$.

Min, S., \& Mentzer, J. T. (2004). Developing and measuring supply chain management concepts. Journal of business logistics, 25(1), 63-99.

Min, S., Mentzer, J. T., \& Ladd, R. T. (2007). A market orientation in supply chain management. Journal of the Academy of Marketing Science, 35(4), 507.

OECD (2010). Regulatory Policy and the Road to Sustainable Growth. Organisation for Economic Co-operation and Development 2010 Report. < http://www.oecd.org/regreform/policyconference/46270065.pdf >

Perrow, C. (1986). Complex organizations: A critical essay, New York: Random House

Pettit, T. J. (2008). Supply chain resilience: development of a conceptual framework, an assessment tool and an implementation process (Doctoral dissertation, The Ohio State University).

Pettit, T. J., Croxton, K. L., \& Fiksel, J. (2013). Ensuring supply chain resilience: development and implementation of an assessment tool. Journal of Business Logistics, 34(1), 46-76.

Pettit, T.J., Fiksel, J. \& Croxton, K.L. (2011). Ensuring supply chain resilience: development of a conceptual framework. Journal of Business Logistics, 31(1), 1-21.

Ponomarov, S. Y., \& Holcomb, M. C. (2009). Understanding the concept of supply chain resilience. The International Journal of Logistics Management, 20(1), 124-143.

Preacher, K.J. \& Hayes, A.F. (2004). SPSS and SAS procedures for estimating indirect effects in simple mediation models. Behavior Research Methods Instruments, and Computers, 36(4), 717-731.

Preacher, K.J. \& Hayes, A.F. (2008). Asymptotic and resampling strategies for assessing and comparing indirect effects in multiple mediator models. Behavior Research Methods, 40(3), 879-891.

Rice, J.B., \& Caniato, F. (2003). Building a Secure and Resilient Supply Network. Supply Chain Management Review, 7(5), $22-30$

Scholten, K., Sharkey Scott, P. \& Fynes, B. (2014). Mitigation processes - antecedents for building supply chain resilience. Supply Chain Management: An International Journal, 19(2), 211-228.

Scott, W. R. (2008). Approaching adulthood: the maturing of institutional theory. Theory and Society, 37(5), 427.

Shapiro, S.P. (2005). Agency theory. Annual Reviews of Sociology, 31, 263-284. 
Sheffi, Y. (2005). The resilient enterprise. MIT Sloan Management Review, 47(1).

Stone, M., (1974). Cross-Validatory Choice and Assessment of Statistical Predictions. Journal of the Royal Statistical Society: Series B (Methodological), [e-journal] 36(2), 111-133. https://doi.org/10.1111/j.2517-6161.1974.tb00994.x

Svensson, G. (2002). A conceptual framework of vulnerability in firms' in-bound and out-bound logistics flows. International Journal of Physical Distribution and Logistics Management, 32(2), 110-3

Trucco, P., \& Ward, D. (2011). A clustering approach to the operational resilience analysis of key resource supply chains (KRSC): The case of fast Moving Consumer Goods. In 2011 IEEE International Conference on Industrial Engineering and Engineering Management (pp. 990-994). IEEE.

Tukamuhabwa, B.R., Stevenson, M., Busby, J. \& Zorzini, M. (2015). Supply chain resilience: definition, review and theoretical foundations for further study. International Journal of Production Research, 53(18), 5592-5623

Ubidia Batallas, J. A. (2014). How to define and measure supply chain resilience (Master's thesis, Burdeos/Kedge Business School/2014).

Umang, S., \& Vipul, J. (2011). Minimizing the vulnerabilities of supply chain: A new framework for enhancing the resilience. Proceedings of the 2011 Institute of Electrical and Electronics

Wagner, S. \& Bode, C., (2006). An empirical investigation into supply chain vulnerability. Journal of Purchasing \& Supply Management, 12(6), 301-312

Waters, D. (2011). Supply chain risk management: vulnerability and resilience in logistics. Kogan Page Publishers

Wetzels, M., Odekerken-Schroder, G. \& Van Oppen, C. (2009). Using PLS path modeling for assessing hierarchical construct models: guidelines and empirical illustration. MIS Quarterly, 33(1), 177-195.

Yunus, E. N. (2012). Drivers of supply chain integration and the role of organizational culture: empirical evidence from Indonesia. Southern Illinois University, Carbondale.

Yunus, E. N., \& Tadisina, S. K. (2016). Drivers of supply chain integration and the role of organizational culture: Empirical evidence from Indonesia. Business Process Management Journal, 22(1), 89-115

Zailani, S., Premkumar, R., \& Fernando, Y. (2008). Factors influencing the effectiveness of operational information sharing within supply chain channels in Malaysia. Operations and Supply Chain Management, 1(2), 85-100.

Zhao, H. (2016). Why collaborative regulation is critical. International Telecommunications Union, 3, 4-21

Zsidisin, G. A., Melnyk, S. A., \& Ragatz, G. L. (2005). An institutional theory perspective of business continuity planning for purchasing and supply management. International Journal of Production Research, 43(16), 3401-3420.

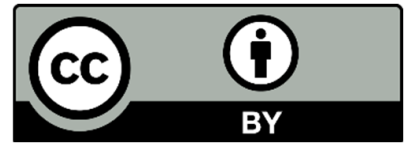

(C) 2022 by the authors; licensee Growing Science, Canada. This is an open access article distributed under the terms and conditions of the Creative Commons Attribution (CCBY) license (http://creativecommons.org/licenses/by/4.0/). 